\title{
Combining X-ray absorption and diffraction to relate structure to the activity in catalysts for $\mathrm{CO}_{2}$ valorization reactions
}

\author{
P.M. Abdala, M. A. Naeem, S. Kim, A. Tsoukalou, A. Fedorov, C.R. Müller \\ Laboratory of Energy Science and Engineering, Institute of Energy Technology, ETH Zurich \\ abdalap@ethz.ch
}

The development of effective catalytic processes for the conversion of $\mathrm{CO}_{2}$ into value-added chemicals or fuels, such as methanol synthesis or the dry reforming of methane (DRM) relies strongly on a rational catalyst design, which in turn requires an in-depth understanding of structure-activity relationships. Due to the inherent complexity of heterogeneous catalytic systems, an arsenal of complementary techniques is required to characterize the catalytic structure (and dynamics thereof) from the atomic-to-nanoscale (under reaction conditions). In this talk, we show how the application of combined X-ray powder diffraction (XRD) and X-ray absorption spectroscopy (XAS) allows obtaining the oxidation state, the local and (nano)crystalline structure of the catalysts providing the basis for the formulation of structure-performance relationships in catalysts for $\mathrm{CO}_{2}$ valorization reactions.

In the first example, we demonstrate how a combined operando XAS-XRD experiment allowed us to relate the evolution of the structure of $\mathrm{In}_{2} \mathrm{O}_{3}$ nanoparticles (NPs) to their activity for $\mathrm{CO}_{2}$ hydrogenation to methanol. ${ }^{[1]}$ The experiments revealed a reductive amorphization of the $\operatorname{In}_{2} \mathrm{O}_{3-x}$ nanocrystallites with time on stream (TOS), leading ultimately to an over-reduction of $\operatorname{In}_{2} \mathrm{O}_{3-x}$ to (molten) $\mathrm{In}^{0}$, in a process that is linked to catalyst deactivation. When the $\mathrm{In}_{2} \mathrm{O}_{3} \mathrm{NPs}$ were supported on a nanocrystalline monoclinic $\mathrm{ZrO}_{2}$ support, we observed the stabilization of the oxidation state of In via the formation of a solid solution $\mathrm{m}-\mathrm{ZrO}_{2}: \mathrm{In}^{\left[{ }^{[2]}\right.} \mathrm{In}$ the second example, we explore a Ni-Fe-based catalyst for the DRM. Combined, operando XAS-XRD experiments allowed us to probe the dynamics of $\mathrm{Ni}-\mathrm{Fe}$ alloying/dealloying with the formation of $\mathrm{FeO}$ to explain the superior stability of the NiFe catalysts compared to a Ni-based analogue, due to a $\mathrm{Fe}-\mathrm{FeO}_{\mathrm{x}}$-based redox cycle. ${ }^{[3]}$ In the last example, combined XAS-XRD experiments are used to shed light on the formation of $\mathrm{Ru}^{0}$ nanoparticles $\left(\mathrm{ca} .1 \mathrm{~nm}\right.$ ) via their exsolution from defective, fluorite-type $\mathrm{Sm}_{2} \mathrm{Ru}_{\mathrm{x}} \mathrm{Ce}_{2-x} \mathrm{O}_{7}$ solid solutions. The resulting exsolved nanoparticles show a high activity and stability for the DRM. ${ }^{[4]}$

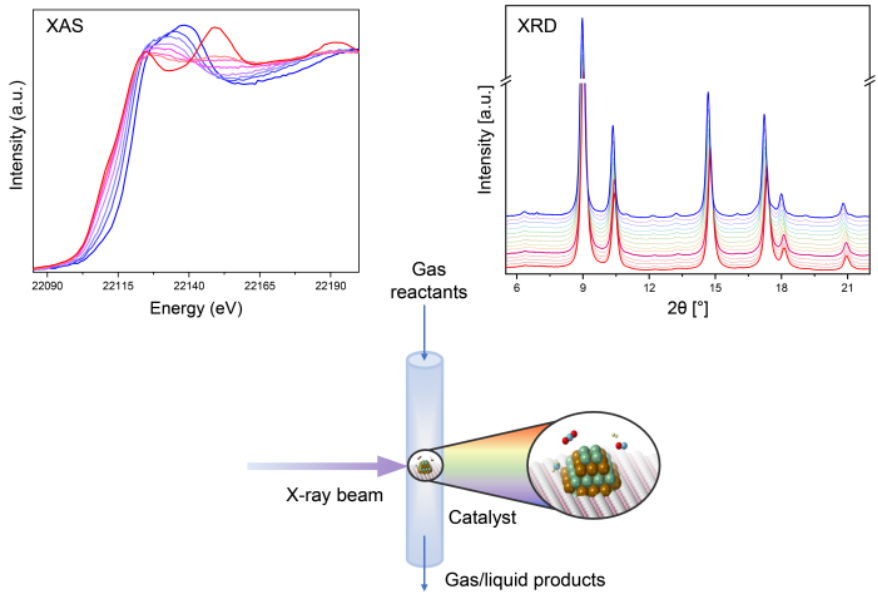

Figure 1. Top: $\mathrm{Ru} \mathrm{K}$-edge XAS and XRD $(0.5 \AA)$ data collected in situ under the reductive treatment of $\mathrm{Sm}_{2} \mathrm{Ru}_{x} \mathrm{Ce}_{2-x} \mathrm{O}_{7},(10 \%$ $\mathrm{H}_{2} / \mathrm{N}_{2}$ ). Bottom: Schematic illustration of the combined XAS-XRD experiments using a capillary flow reactor.

[1] A. Tsoukalou, P. M. Abdala, D. Stoian, X. Huang, M.-G. Willinger, A. Fedorov, C. R. Müller, J. Am. Chem. Soc. 2019, 141, 13497-13505.

[2] A. Tsoukalou, P. M. Abdala, A. Armutlulu, E. Willinger, A. Fedorov, C. R. Müller, ACS Catal. 2020, 10, 10060-10067.

[3] S. M. Kim, P. M. Abdala, T. Margossian, D. Hosseini, L. Foppa, A. Armutlulu, W. van Beek, A. Comas-Vives, C. Copéret, C. Müller, J. Am. Chem. Soc. 2017, 139, 1937-1949.

[4] M. A. Naeem, P. M. Abdala, A. Armutlulu, S. M. Kim, A. Fedorov, C. R. Müller, ACS Catal. 2020, 10, $1923-1937$.

Keywords: catalyst, X-ray absorption spectroscopy, X-ray powder diffraction, $\mathrm{CO}_{2}$ valorization 